\title{
Analisis Peningkatan Pelayanan Stasiun Bogor Terhadap Kepuasan Pengguna Jasa Kereta Api Dengan Metode Importance Performance Analysis (IPA)
}

\author{
Azhar Hermawan Riyanto', Bambang Riyanto²
}

Diterima : 21 Agustus 2015

Disetujui : 31 Desember 2015

\begin{abstract}
Excellent service is part of the target PT. Kereta Api Indonesia (Persero) to maximize efforts in innovation services, one of which implementation is the existence of Bogor Station, This study uses a quantitative approach, according to the basic assumptions axiology quantitative approach seeks explanation of the relationship between the variables studied, while the research method used is descriptive analysis, which aims to explain or describe further the pattern of correlation, the relationship between two or more variables studied, technique of analysis by analyzing the performance of services with Servqual Service, methods of science and CSI and utility station facilities in terms of user services based on standards Minimum service station where respondents are users of services in Bogor Station. Based on the analysis we can conclude CSI scores of this study is $62 \%$, which indicates the overall service of Bogor Station are included in the category quite satisfied and there are five attributes that a top priority for immediate improved performance, among others, the availability of the number of toilets, availability and comfort of the lounge (waiting room) passengers, cleanliness and comfort toilet, comfort and ease up/down passenger (Peron) and the availability of information and the announcement of train travel.
\end{abstract}

Keywords: Service Station, Method Importance Performance Analysis (IPA), Utilities Station Facility

\begin{abstract}
ABSTRAK
Excellent service merupakan bagian dari sasaran PT. Kereta Api Indonesia (Persero) untuk memaksimalkan upaya dalam inovasi pelayanannya, dimana salah satunya implementasinya adalah dengan keberadaan Stasiun Bogor, Penelitian ini menggunakan pendekatan kuantitatif, menurut asumsi dasar aksiologi pendekatan kuantitatif berusaha mencari penjelasan hubungan antara variabel-variabel yang diteliti, sedangkan metode penelitian yang digunakan adalah analisis deskriptif, yang bertujuan untuk menjelaskan atau mendiskripsikan lebih jauh pola hubungan korelasi, keterkaitan antara dua atau lebih variabel yang diteliti, teknik analisis dengan menganalisa kinerja pelayanan dengan Servqual Service, metode IPA lalu CSI dan utilitas fasilitas stasiun ditinjau dari pengguna jasa berdasarkan Standar Pelayanan Minimum Stasiun dimana respondennya yaitu pengguna jasa di Stasiun Bogor. Berdasarkan hasil analisa tersebut dapat disimpulkan nilai CSI dari penelitian ini yaitu 62 \% yang mengindikasikan secara keseluruhan pelayanan Stasiun Bogor termasuk dalam kategori cukup puas dan terdapat 5 atribut yang menjadi prioritas utama untuk segera ditingkatkan kinerjanya antara lain, ketersediaan jumlah toilet, ketersediaan dan kenyamanan ruang tunggu (waiting room) penumpang, kebersihan dan kenyamanan toilet, kenyamanan dan kemudahan naik/turun penumpang (Peron) dan ketersediaan informasi dan pengumuman perjalanan kereta api.
\end{abstract}

Kata kunci : Pelayanan Stasiun, Metode Importance Performance Analysis (IPA), Utilitas Fasilitas Stasiun

\footnotetext{
${ }^{1}$ Sekolah Tinggi Transportasi Darat

Kontak penulis: azharhermawan@yahoo.co.id

2 Dosen Magister Pembangunan Wilayahdan Kota, Undip Semarang, Jawa Tengah
} 
Hermawan | Analisis Peningkatan Pelayanan Stasiun Bogor Terhadap Kepuasan Pengguna Jasa Kereta Api Dengan Metode Importance Performance Analysis (IPA)

\section{PENDAHULUAN}

Stasiun juga sebagai salah satu simpul transportasi memiliki peranan penting dalam penyelenggaraan perkeretaapian, excellent service merupakan bagian dari sasaran PT. Kereta Api Indonesia (Persero) untuk memaksimalkan upaya dalam inovasi pelayanannya, dimana salah satunya implementasinya adalah dengan keberadaan Stasiun Bogor. Stasiun Bogor juga merupakan Stasiun dengan jumlah penumpang operasi cukup besar dan terpadat tiap tahunnya jika dibandingkan dengan stasiun lain di wilayah DAOP I Jakarta. Namun pada kenyataannya, berdasarkan hasil observasi di lapangan masih banyak ditemukan keluhan masyarakat terhadap pelayanan di Stasiun Bogor yang masih belum optimal dalam memberikan pelayanan terhadap pengguna jasa terutama dalam hal penyedian fasilitas pokok, fasilitas penunjang, dan fasilitas khusus yang ada di Stasiun antara lain seringnya keterlambatan jadwal keberangkatan dan kedatangan kereta api sehingga menimbulkan kepadatan di stasiun, juga ketersediaan informasi dan layanan pendukung lainnya yang belum tersedia secara memadai antrian loket yang padat pada saat jam sibuk, fasilitas naik dan turun penumpang (peron) yang kurang nyaman dan ketersediaan ruang tunggu yang masih kurang memadai.

Penelitian ini bertujuan untuk memberikan rekomendasi perbaikan prioritas utama tingkat kepuasaan pengguna jasa kepada penyedia jasa di Stasiun Bogor DAOP I Jakarta terhadap peningkatan pelayanan dan fasilitas di Stasiun Bogor, Sasaran dalam penelitian yang dimaksudkan merupakan penjabaran pencapaian tujuan penelitian. Adapun sasaran penelitian ini adalah mengetahui nilai Customer Satisfaction Indeks (CSI) melalui perhitungan nilai kinerja dan tingkat kepentingan pengguna jasa terhadap pelayanan di Stasiun Bogor dengan metode IPA, mengetahui Indikator pelayanan di Stasiun Bogor yang menjadi prioritas utama (hasil perhitungan IPA) perbaikan dan menghitung kebutuhan ruang tunggu dalam Stasiun berdasarkan hasil dari prioritas utama perbaikan fasilitas stasiun agar kinerja lebih optimal berdasarkan Standar Pelayanan Minimum Untuk Angkutan Orang Dengan Kereta Api dan memberikan usulan perbaikan terhadap peningkatan kualitas pelayanan kepada penyedia jasa di Stasiun Bogor.

\section{METODOLOGI PENELITIAN}

Penelitian ini menggunakan pendekatan kuantitatif menurut asumsi dasar aksiologi pendekatan kuantitatif berusaha mencari penjelasan hubungan antara variabel-variabel yang diteliti, sedangkan metode penelitian yang digunakan adalah analisis deskriptif, yang bertujuan untuk menjelaskan atau mendiskripsikan lebih jauh pola hubungan korelasi, keterkaitan antara dua atau lebih variabel yang diteliti. Pengumpulan data dilakukan secara primer (kuesioner, wawancara, observasi, dokumentasi) dan secara sekunder (telaah dokumen instansi). Teknik pengambilan sampel dalam penelitian ini dilakukan secara acak (random sampling). Ukuran sampel yang sesuai adalah antara 100-200, Karena jumlah indikator dalam penelitian ini seluruhnya berjumlah 20, maka jumlah sampel yang digunakan dalam penelitian ini sebesar 200 sampel.

\section{GAMBARAN UMUM}

Kota Bogor berjarak \pm 54 km dari lbu Kota Negara DKI Jakarta, secara geografis terletak di antara $106,48^{\circ}$ Bujur Timur dan 6,36 Lintang Selatan. Secara administrasi Kota Bogor termasuk ke dalam Propinsi Jawa Barat dan dikelilingi oleh Wilayah Kabupaten Bogor, Kota Bogor terdiri dari 
6 (enam) Kecamatan, yaitu: Kecamatan Kota Bogor Utara, Kecamatan Kota Bogor Timur, Kecamatan Kota Bogor Barat, Kecamatan Kota Bogor Tengah, Kecamatan Kota Bogor Selatan dan Kecamatan Tanah Sareal, dengan 22 kelurahan dan 46 desa. Luas Wilayah Kota Bogor Tahun 2009 adalah seluas 111,73 km². Stasiun Bogor dahulu bernama Stasiun Buitenzorg (kode: BOO) adalah stasiun kereta api yang berada di wilayah Kec. Bogor Tengah, Kota Bogor, DAOP 1 Jakarta. Stasiun Bogor termasuk stasiun kelas Besar Tipe A, yang dibangun pada tahun 1881. Stasiun yang berada di ketinggian $+246 \mathrm{mdpl}$ ini, sebagian besar melayani $98 \%$ perjalanan Kereta Rel Listrik (KRL) yang melayani kawasan Jabodetabek atau sering disebut sebagai Commuter Line, yakni menuju Stasiun Jakarta Kota dan Stasiun Jatinegara serta melayani kereta api lokal Pangrango menuju Sukabumi.

\section{KAJIAN TEORI}

\section{Hubungan Antara Kualitas Pelayanan Terhadap Kepuasan Pengguna Jasa}

Menurut Tjiptono (1996), kualitas memiliki hubungan yang erat dengan kepuasan konsumen, sehingga memberikan suatu dorongan kepada konsumen untuk menjalin ikatan hubungan yang kuat dengan perusahaan. Menurut Parasuraman (1985) dalam mengevaluasi kualitas terhadap jasa yang bersifat intagible (non fisik) dapat menggunakan analisis SERVQUAL (service quality), yaitu perbedaaan antara kenyataan dan harapan konsumen atas pelayanan yang mereka terima/peroleh. Harapan konsumen ini didasarkan pada informasi dari mulut ke mulut, kebutuhan pribadi, pengalaman di masa lampau dan komunikasi eksternal (iklan sebagai bentuk promosi). Analisis servqual (service quality) yang terdiri dari lima dimensi kualitas jasa, yaitu:

a. Bukti fisik (tangibles)

Penampilan dan kemampuan sarana dan prasarana fisik perusahaan dan keadaan lingkungan sekitarnya adalah bukti nyata dari pelayanan yang diberikan oleh pemberi layanan jasa yang meliputi fasilitas fisik (gedung), teknologi (peralatan dan perlengkapan yang digunakan), penampilan pegawai serta sarana komunikasi.

b. Kehandalan (reliability)

Kemampuan perusahaan untuk memberikan pelayanan sesuai yang dijanjikan secara akurat dan terpercaya. Hal ini harus sesuai dengan harapan konsumen seperti kinerja yang tepat waktu, pelayanan tanpa kesalahan, sikap simpatik dan terpercaya.

c. Ketanggapan (responsiveness)

Suatu kemauan untuk membantu dan memberikan pelayanan yang cepat (responsive) dan tepat kepada konsumen dengan penyampaian informasi yang jelas.

d. Jaminan dan kepastian (assurance)

Pengetahuan, kesopan-santunan dan kemampuan para pegawai perusahaan untuk menumbuhkan rasa percaya konsumen kepada perusahaan. Terdiri dari komponen: komunikasi (communication), kredibilitas (credibility), keamanan (security) dan kompetensi (competence) serta sopan santun (courtesy).

e. Perhatian yang tulus (empathy)

Memberikan perhatian yang tulus dan bersifat individual atau pribadi yang diberikan kepada konsumen dengan berupaya memahami keinginan konsumen.

\section{Importance Performance Analysis (IPA)}

Teknik (Importance Performance Analysis) IPA dilakukan dimana responden diminta untuk meranking berbagai elemen (atribut) dari penawaran berdasarkan derajat pentingnya setiap elemen dan seberapa baik kinerja perusahaan dalam masing-masing elemen (importance/performance ratings). Teknik ini dikenal pula dengan istilah Importance Performance Analysis (Martilla dan James, 1997). Diagram kartesius Importance Performance Analysis 
Hermawan | Analisis Peningkatan Pelayanan Stasiun Bogor Terhadap Kepuasan Pengguna Jasa Kereta Api Dengan Metode Importance Performance Analysis (IPA)

merupakan suatu diagram yang dibagi menjadi 4 (empat) bagian dan dibatasi oleh 2 (dua) buah garis yang berpotongan tegak lurus pada titik $(x, y)$, dimana $x$ merupakan rata-rata dari rata-rata skor penilaian kinerja, sedangkan y merupakan rata-rata dari skor kepentingan pengguna jasa. Hasil perhitungan tersebut diletakkan dalam kuadran yang ada di dalam diagram kartesius tersebut, yaitu :

a. Kuadran I (Prioritas Utama)

Wilayah yang memuat item-item dengan tingkat kepentingan yang relatif tinggi dengan tingkat kinerja yang rendah, sehingga kenyataanya belum sesuai dengan harapan pengguna. Item-item yang termasuk dalam kuadran ini harus segera ditingkatkan kinerjanya.

b. Kuadran II (Pertahankan Prestasi)

Wilayah yang memuat item-item yang memiliki tingkat kepentingan relatif tinggi dengan tingkat kepuasan yang relatif tinggi pula. Item yang termasuk dalam kuadran ini dianggap sebagai faktor penunjang bagi kepuasan pengguna jasa sehingga harus tetap dipertahankan karena semua item ini menjadikan produk atau jasa tersebut unggul di mata pengguna.

c. Kuadran III (Prioritas Rendah)

Wilayah ini memuat item-item dengan tingkat kepentingan yang relatif rendah dan kenyataan kinerjanya tidak terlalu istimewa dengan tingkat kepuasan yang relatif rendah. Item yang termasuk dalam kuadran ini memberikan pengaruh yang sangat kecil terhadap manfaat yang dirasakan oleh pengguna.

d. Kuadran IV (Berlebihan)

Item-item yang dimuat dalam wilayah kuadran ini yaitu dengan tingkat kepentingan yang relatif rendah dan dirasakan oleh pengguna terlalu berlebihan dengan tingkat kepuasan yang relatif tinggi. Biaya yang digunakan untuk menunjang item yang masuk ke dalam kuadran ini dapat dikurangi untuk menghemat biaya pengeluaran. Diagram kartesius tersebut adalah sebagai berikut :

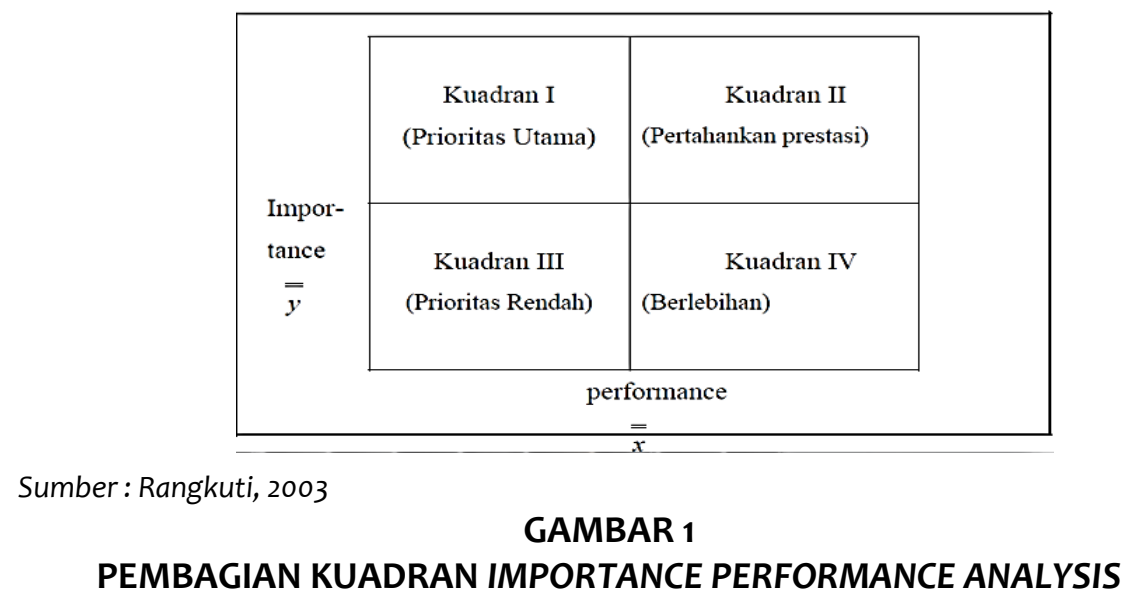

\section{Utilitas Fasilitas Stasiun}

Utilitas Fasilitas Stasiun adalah suatu kelengkapan fasilitas bangunan yang digunakan untuk menunjang tercapainya unsur-unsur kenyamanan, kesehatan, keselamatan, kemudian kominikasi dan mobilitas dalam pelayanan jasa. Analisis teknis mengacu pada Peraturan Menteri Perhubungan Nomor 9 Tahun 2011 Tentang Standar Pelayanan 
Minimum Untuk Angkutan Orang Dengan Kereta Api. Adapun jenis-jenis utilitas fasilitas stasiun dapat jelaskan sebagai berikut :

a. Fasilitas Informasi

Informasi, baik berupa visual maupun audio menyangkut beberapa hal yang perlu diketahui pengguna jasa angkutan penumpang yang sedang berada di stasiun.

b. Loket

Loket, menyangkut baik waktu pelayanan dan informasi yang perlu diketahui oleh penumpang kereta api. Namun didalam standar pelayanan minimum belum diatur mengenai dimensi ukuran loket, khususnya yang mengakomodasi pelayanan untuk para penumpang.

c. Ruang Tunggu

Ruang Tunggu disesuaikan berdasarkan jumlah penumpang yang menggunakan pelayanan kereta api di stasiun.

d. Tempat Ibadah

Dalam Standar Pelayanan Minimum hanya di atur mengenai keberadaan ruang ibadah dan kapasitas minimumnya. Sementara petunjuk cara menghitung kapasitas belum dicantumkan.

e. Toilet

Dalam Standar Pelayanan Minimum hanya diatur mengenai keberadaan toilet dan kapasitas minimumnya.

f. Parkir

Dalam Standar Playanan Minimum hanya diatur mengenai peruntukan, aksesibilitas dan kapasitas minimumnya. Sementara petunjuk cara menghitung kapasitas belum dicantumkan.

g. Fasilitas kemudahan naik/turun penumpang (Peron)

Diatur berdasarkan jumlah penumpang yang dilayani dan panjang kereta api yang melayani di stasiun.

h. Fasilitas Penyandang Cacat

Fasilitas yang dimaksud adalah disediakannya pelayanan khusus bagi penumpang penyandang cacat agar memudahkan penumpang tersebut untuk mendapatkan tiket dan naik keatas kereta api.

i. Fasilitas Kesehatan

Fasilitas yang dimaksud adalah fasilitas yang disediakan untuk penanganan darurat yang mungkin terjadi diwilayah stasiun. Fasilitas dan peralatan kesehatan ini harus disediakan untuk pertolongan pertama bagi kesehatan penumpang.

j. Fasilitas Keselamatan dan Keamanan

Fasilitas yang dimaksud adalah peralatan penyelamatan darurat dalam bahaya seperti kebakaran, bencana alam, dan kecelakaan, serta penjagaan dari kemungkinan tindakan kriminal.

\section{ANALISIS IMPORTANCE PERFORMANCE ANALYSIS (IPA)}

\section{Matriks Importance Performance Analysis (IPA)}

Untuk mengetahui atribut yang harus ditingkatkan kinerjanya untuk meningkatkan kepuasan pelanggan yaitu yang termasuk ke dalam kategori prioritas utama dan prioritas rendah, maka dibuatlah matriks IPA, dimana nilai dari matriks IPA diperoleh dari hasil perpotongan antara skor rata-rata kinerja $(\bar{X})$ dan skor rata-rata kepentingan $(\bar{Y})$, sebagai berikut: 
Hermawan | Analisis Peningkatan Pelayanan Stasiun Bogor Terhadap Kepuasan Pengguna Jasa Kereta Api Dengan Metode Importance Performance Analysis (IPA)

JPWK 11 (4)

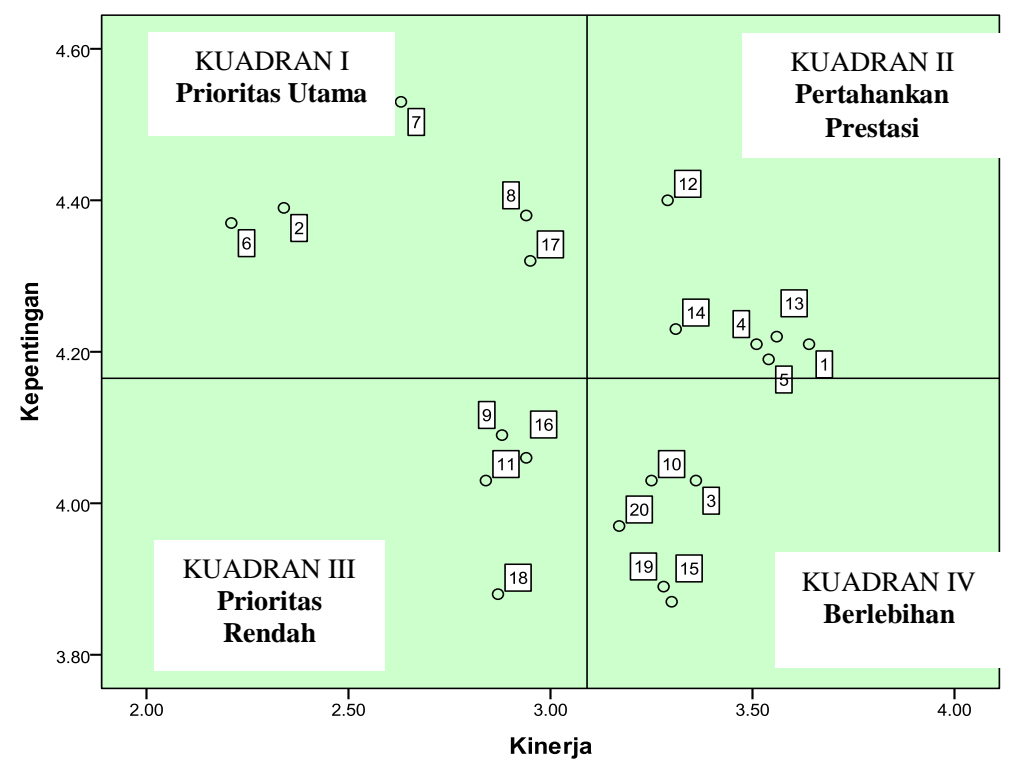

Sumber: Hasil analisis, 2015

\section{GAMBAR 2}

MATRIKS IPA

Dari gambar matriks di atas, dapat diketahui bahwa:

a. Kuadran I (Prioritas Utama)

Penanganan atribut yang berada dalam kuadran ini perlu diprioritaskan perbaikannya, karena keberadaan atribut-atribut inilah yang dinilai sangat penting oleh pengguna jasa, akan tetapi kinerjanya masih belum memuaskan,atribut pelayanan yang berada di kuadran 1 (prioritas utama) yaitu atribut 2, 6, 7, 8 dan 17.

b. Kuadran II (Pertahankan Prestasi)

Kinerja atribut yang termasuk dalam kuadran ini perlu dipertahankan, karena pada umumnya tingkat pelaksanaannya telah sesuai dengan tingkat kepentingan dan harapan penumpang, atribut pelayanan yang berada di kuadran II (pertahankan prestasi) antara lain atribut 1. 4, 5, 12, 13 dan 14.

c. Kuadran III (Prioritas Rendah)

Keberadaan atribut yang berada dalam kuadran ini masih dianggap kurang penting bagi pelanggan dan kinerjanya termasuk dalam kategori biasa atau cukup, atribut pelayanan yang berada di kuadran III (prioritas rendah) antara lain atribut 9, 11, 16 dan 18.

d. Kuadran IV (Berlebihan)

Pelaksanaan kinerja atribut dalam kuadran ini dilakukan dengan sangat baik dan memuaskan, akan tetapi bagi pengguna jasa itu sendiri mengganggap tidak terlalu penting terhadap keberadaan atribut ini, atribut pelayanan yang berada di kuadran IV (berlebihan) antara lain atribut 3, 10, 15, 19 dan 20.

\section{Nilai Customer Satisfaction Index (CSI)}

Setelah mengetahui hasil dari matriks IPA, maka untuk mengetahui hasil perhitungan nilai indeks kepuasaan keseluruhan pelayanan di Stasiun Bogor yang bertujuan untuk mengetahui kriteria tingkat kepuasan responden secara menyeluruh di Stasiun Bogor 
JPWK 11 (4)

Hermawan | Analisis Peningkatan Pelayanan Stasiun Bogor Terhadap Kepuasan Pengguna Jasa Kereta Api Dengan Metode Importance Performance Analysis (IPA)

yang diperoleh dari skor rata-rata tingkat kinerja dan kepentingan sehingga di dapat

hasil pada tabel 5 di bawah ini.

TABEL 1

NILAI INDEKS KEPUASAN (CSI)

\begin{tabular}{|c|c|c|c|c|c|}
\hline No & Kualitas Pelayanan & $\begin{array}{c}\text { Skor } \\
\text { Rata-Rata } \\
\text { Kinerja } \\
(\bar{X})\end{array}$ & $\begin{array}{c}\text { Skor } \\
\text { Rata-Rata } \\
\text { Kepentingan } \\
(\bar{Y})\end{array}$ & $\begin{array}{l}\text { Weighted } \\
\text { Factor (Wf) } \\
\text { (\%) }\end{array}$ & $\begin{array}{l}\text { Weighting } \\
\text { Score } \\
\text { (Ws) }\end{array}$ \\
\hline 1 & $\begin{array}{l}\text { Ketersediaan dan kenyamanan fasilitas } \\
\text { umum (ATM gallery dan minimarket) }\end{array}$ & 3.64 & 4.21 & 5.06 & 0.18 \\
\hline 2 & $\begin{array}{l}\text { Ketersediaan dan kenyamanan ruang } \\
\text { tunggu (waiting room) penumpang }\end{array}$ & 2.34 & 4.39 & 5.27 & 0.12 \\
\hline 3 & $\begin{array}{l}\text { Ketersediaan dan kenyamanan area } \\
\text { parkir }\end{array}$ & 3.36 & 4.03 & 4.84 & 0.16 \\
\hline 4 & Ketersediaan dan kondisi loket tiket & 3.51 & 4.21 & 5.05 & 0.18 \\
\hline 5 & $\begin{array}{l}\text { Kenyamanan dan ketersediaan pintu } \\
\text { tapping tiket (e-ticketing) saat masuk } \\
\text { dan keluar }\end{array}$ & 3.54 & 4.19 & 5.03 & 0.18 \\
\hline 6 & Ketersediaan jumlah toilet & 2.21 & 4.37 & 5.24 & 0.12 \\
\hline 7 & Kebersihan dan kenyamanan toilet & 2.63 & 4.53 & 5.44 & 0.14 \\
\hline 8 & $\begin{array}{l}\text { Kenyamanan dan kemudahan naik/ } \\
\text { turun penumpang (Peron) }\end{array}$ & 2.94 & 4.38 & 5.26 & 0.15 \\
\hline 9 & $\begin{array}{l}\text { Kondisi dan kenyamanan tempat } \\
\text { ibadah (musholla) }\end{array}$ & 2.88 & 4.09 & 4.91 & 0.14 \\
\hline 10 & Kebersihan dan kerapian lingkungan & 3.25 & 4.03 & 4.84 & 0.16 \\
\hline 11 & $\begin{array}{l}\text { Ketersediaan dan kondisi fasilitas } \\
\text { keselamatan (alat pemadam } \\
\text { kebakaran, sirine dan jalur evakuasi) }\end{array}$ & 2.84 & 4.03 & 4.84 & 0.14 \\
\hline 12 & $\begin{array}{l}\text { Ketepatan jadwal berangkat dan tiba } \\
\text { kereta api }\end{array}$ & 3.29 & 4.40 & 5.29 & 0.17 \\
\hline 13 & $\begin{array}{l}\text { Prosedur dan pelayanan pembelian } \\
\text { tiket yang mudah dan aman }\end{array}$ & 3.56 & 4.22 & 5.06 & 0.18 \\
\hline 14 & $\begin{array}{l}\text { Kepekaan dan ketanggapan pihak } \\
\text { stasiun (pegawai KCJ, petugas } \\
\text { kebersihan dan security) dalam } \\
\text { menghadapi serta mengatasi masalah } \\
\text { pengaduan dan keluhan penumpang }\end{array}$ & 3.31 & 4.23 & 5.08 & 0.17 \\
\hline 15 & $\begin{array}{l}\text { Ketersediaan dan ketanggapan } \\
\text { petugas keamanan dalam menjaga } \\
\text { keamanan dan ketertiban }\end{array}$ & 3.30 & 3.87 & 4.65 & 0.15 \\
\hline 16 & $\begin{array}{l}\text { Kecepatan pelayanan pembelian tiket } \\
\text { dan ketanggapan petugas tiket di } \\
\text { loket. }\end{array}$ & 2.94 & 4.06 & 4.88 & 0.14 \\
\hline 17 & $\begin{array}{l}\text { Ketersediaan informasi dan } \\
\text { pengumuman perjalanan kereta api }\end{array}$ & 2.95 & 4.32 & 5.18 & 0.15 \\
\hline 18 & $\begin{array}{l}\text { Ketersediaan dan kenyamanan ruang } \\
\text { kesehatan (poliklinik) }\end{array}$ & 2.87 & 3.88 & 4.66 & 0.13 \\
\hline 19 & $\begin{array}{l}\text { Keramahan dan kesopanan petugas } \\
\text { tiket di loket }\end{array}$ & 3.28 & 3.89 & 4.67 & 0.15 \\
\hline
\end{tabular}


Hermawan | Analisis Peningkatan Pelayanan Stasiun Bogor Terhadap Kepuasan Pengguna Jasa Kereta Api Dengan Metode Importance Performance Analysis (IPA)

JPWK 11 (4)

\begin{tabular}{|c|c|c|c|c|c|}
\hline No & Kualitas Pelayanan & $\begin{array}{c}\text { Skor } \\
\text { Rata-Rata } \\
\text { Kinerja } \\
(\bar{X})\end{array}$ & $\begin{array}{c}\text { Skor } \\
\text { Rata-Rata } \\
\text { Kepentingan } \\
(\bar{Y})\end{array}$ & $\begin{array}{c}\text { Weighted } \\
\text { Factor (Wf) } \\
(\%)\end{array}$ & $\begin{array}{c}\text { Weighting } \\
\text { Score } \\
\text { (Ws) }\end{array}$ \\
\hline 20 & $\begin{array}{l}\text { Ketersediaan dan kondisi fasilitas } \\
\text { penyandang cacat, Ibu hamil dan } \\
\text { menyusui }\end{array}$ & 3.17 & 3.97 & 4.76 & 0.15 \\
\hline Total & 61,76 & 83,25 & 100,00 & \\
\hline Weighted total & & & & 3,08 \\
\hline
\end{tabular}

Sumber: Hasil analisis, 2015

Dari hasil perhitungan CSI pada Tabel 1 didapat nilai 62\% yang mengindikasikan tingkat kepuasan pengguna jasa terpenuhi terhadap pelayanan di Stasiun Bogor termasuk dalam kategori cukup puas, dimana setelah dilakukan perhitungan skor rata-rata kinerja dan kepentingan.

Berdasarakan perhitungan skor rata-rata kepentingan $(\bar{Y})$ dikurangi skor rata-rata kinerja $(\bar{X})$ dapat diketahui nilai kesenjangan dari setiap atribut pelayanan di Stasiun Bogor, dimana perhitungan nilai kesenjangan bertujuan untuk mengetahui skor selisih terbesar nilai kesenjangan sehingga perlu segera dilakukan perbaikan atribut kualitas pelayanan tersebut, untuk lebih jelasnya dapat dilihat seperti tabel dibawah ini.

TABEL 2

PERHITUNGAN NILAI KESENJANGAN (GAP)

\begin{tabular}{|c|c|c|c|c|}
\hline No & Kualitas Pelayanan & $\begin{array}{l}\text { Skor Rata-Rata } \\
\text { Kepentingan }(\bar{Y})\end{array}$ & $\begin{array}{l}\text { Skor Rata- } \\
\text { Rata Kinerja } \\
(\bar{X})\end{array}$ & Gap \\
\hline 1 & $\begin{array}{l}\text { Ketersediaan dan kenyamanan fasilitas umum (atm } \\
\text { gallery dan minimarket) }\end{array}$ & 4.21 & 3.64 & -0.57 \\
\hline 2 & $\begin{array}{l}\text { Ketersediaan dan kenyamanan ruang tunggu } \\
\text { (waiting room) penumpang }\end{array}$ & $4 \cdot 39$ & 2.34 & -2.06 \\
\hline 3 & Ketersediaan dan kenyamanan area parkir & 4.03 & 3.36 & -0.68 \\
\hline 4 & Ketersediaan dan kondisi loket tiket & 4.21 & 3.51 & -0.70 \\
\hline 5 & $\begin{array}{l}\text { Kenyamanan dan ketersediaan pintu tapping tiket } \\
\text { (e-ticketing) saat masuk dan keluar }\end{array}$ & 4.19 & 3.54 & -0.65 \\
\hline 6 & Ketersediaan jumlah toilet & 4.37 & 2.21 & -2.16 \\
\hline 7 & Kebersihan dan kenyamanan toilet & 4.53 & 2.63 & -1.90 \\
\hline 8 & $\begin{array}{l}\text { Kenyamanan dan kemudahan naik/ turun } \\
\text { penumpang (Peron) }\end{array}$ & 4.38 & 2.94 & -1.44 \\
\hline 9 & Kondisi dan kenyamanan tempat ibadah (Musholla) & 4.09 & 2.88 & -1.21 \\
\hline 10 & Kebersihan dan kerapian lingkungan & 4.03 & 3.25 & -0.78 \\
\hline 11 & $\begin{array}{l}\text { Ketersediaan dan kondisi fasilitas keselamatan (alat } \\
\text { pemadam kebakaran, sirine dan jalur evakuasi) }\end{array}$ & 4.03 & 2.84 & -1.19 \\
\hline 12 & Ketepatan jadwal berangkat dan tiba kereta api & 4.40 & 3.29 & -1.11 \\
\hline
\end{tabular}



Kereta Api Dengan Metode Importance Performance Analysis (IPA)

\begin{tabular}{|c|c|c|c|c|}
\hline No & Kualitas Pelayanan & $\begin{array}{l}\text { Skor Rata-Rata } \\
\text { Kepentingan }(\bar{Y})\end{array}$ & $\begin{array}{l}\text { Skor Rata- } \\
\text { Rata Kinerja } \\
(\bar{X})\end{array}$ & Gap \\
\hline 13 & $\begin{array}{l}\text { Prosedur dan pelayanan pembelian tiket yang } \\
\text { mudah dan aman }\end{array}$ & 4.22 & 3.56 & -0.66 \\
\hline 14 & $\begin{array}{l}\text { Kepekaan dan ketanggapan pihak stasiun (pegawai } \\
\text { KCJ, petugas kebersihan dan security) dalam } \\
\text { menghadapi serta mengatasi masalah pengaduan } \\
\text { dan keluhan penumpang }\end{array}$ & 4.23 & 3.31 & -0.92 \\
\hline 15 & $\begin{array}{l}\text { Ketersediaan dan ketanggapan petugas keamanan } \\
\text { dalam menjaga keamanan dan ketertiban }\end{array}$ & 3.87 & 3.30 & -0.58 \\
\hline 16 & $\begin{array}{l}\text { Kecepatan pelayanan pembelian tiket dan } \\
\text { ketanggapan petugas tiket di loket. }\end{array}$ & 4.06 & 2.94 & -1.13 \\
\hline 17 & $\begin{array}{l}\text { Ketersediaan informasi dan pengumuman } \\
\text { perjalanan kereta api }\end{array}$ & $4 \cdot 32$ & 2.95 & -1.37 \\
\hline 18 & $\begin{array}{l}\text { Ketersediaan dan kenyamanan ruang kesehatan } \\
\text { (poliklinik) }\end{array}$ & 3.88 & 2.87 & -1.01 \\
\hline 19 & Keramahan dan kesopanan petugas tiket di loket & 3.89 & 3.28 & -0.61 \\
\hline 20 & $\begin{array}{l}\text { Ketersediaan dan kondisi fasilitas penyandang } \\
\text { cacat, Ibu hamil dan menyusui }\end{array}$ & 3.97 & 3.17 & -0.80 \\
\hline
\end{tabular}

\section{Analisis Utilitas Fasilitas Stasiun Berdasarkan Standar Pelayanan Minimum Stasiun Menurut Peraturan Menteri Perhubungan Nomor 9 Tahun 2011}

Berdasarkan hasil uraian dan analisis pengolahan data dengan menggunakan metode Importance Performance Analisys (IPA) maka diketahui unsur-unsur dari kinerja pelayanan yang masih perlu diperhatikan. Untuk meningkatkan utilitas fasilitas Stasiun Bogor di masa yang akan datang perlu dilakukan beberapa perbaikan utama dari beberapa atribut yang memang sangat membutuhkan perbaikan untuk memberikan kepuasaan dan kenyamanan bagi para pengguana jasa kereta api di Stasiun Bogor, antara lain :

\section{1) Analisis Ketersediaan jumlah toilet di Stasiun Bogor}

Analisis dilakukan berdasarkan tanggapan pengguna jasa berkaitan mengenai ketersediaan dan penempatan yang diatur dalam Peraturan Menteri Perhubungan Nomor 9 Tahun 2011 Tentang Standar Pelayanan Minimum Untuk Angkutan Orang Dengan Kereta Api. Menurut Peraturan Menteri Perhubungan Nomor 9 Tahun 2011 Tentang Standar Pelayanan Minimum untuk toilet Pria jumlah toilet yang harus tersedia yaitu 6 normal dan 2 penyandang cacat dan Wanita 6 normal dan 2 penyandang cacat, sehingga perlu penambahan mengenai jumlah tolet yang berada di Stasiun Bogor untuk diletakan pada dua area terpisah di sisi utara maupun selatan stasiun dan satu tolet di luar stasiun diperuntukkan untuk penumpang yang antri tiket untuk mempermudah pengguna jasa di Stasiun Bogor.

2) Ketersediaan dan kenyamanan ruang tunggu (waiting room) penumpang

Berdasarkan Standar Pelayanan Minimum Stasiun Menurut Peraturan Menteri Perhubungan Nomor 9 Tahun 2011 kebutuhan ruang tunggu di dalam stasiun, maka dapat diketahui hasil perhitungan kebutuhan ruang tunggu pada tabel di bawah ini. 
Hermawan | Analisis Peningkatan Pelayanan Stasiun Bogor Terhadap Kepuasan Pengguna Jasa Kereta Api Dengan

TABEL 3

KEBUTUHAN RUANG TUNGGU

\begin{tabular}{|c|c|c|c|c|}
\hline No. & Uraian & Jumlah & Ukuran Per Unit & $\begin{array}{c}\text { Kebeutuhan } \\
\text { Ruang }\end{array}$ \\
\hline 1 & Ruang gerak manusia & 2278 orang & $2.2 \mathrm{~m} \times 1.1 \mathrm{~m}=2.42 \mathrm{~m}^{2}$ & $5 \cdot 512,76 \mathrm{~m}^{2}$ \\
\hline 2 & Tempat duduk & 20 unit & $3 \mathrm{~m} \times 0.5 \mathrm{~m}=1.5 \mathrm{~m}^{2}$ & $30 m^{2}$ \\
\hline 3 & Kebutuhan ruang & & $3.92 \mathrm{~m}^{2}$ & $5,542.76 \mathrm{~m}^{2}$ \\
\hline 4 & Ruang sirkulasi (15\%) & & & $831.41 \mathrm{~m}^{2}$ \\
\hline & Total & & & $6,374 \cdot 17 \mathrm{~m}^{2}$ \\
\hline
\end{tabular}

Sumber : Hasil Analisis 2015

Berdasarkan perhitungan kebutuhan ruang tunggu di stasiun Bogor maka pihak stasiun agar menyiapkan lahan seluas $6,374 \mathrm{~m}^{2}$, untuk ruang tunggu di Stasiun Bogor yang saat ini belum tersedia untuk menunjang peningkatan pelayanan yang di berikan Stasiun Bogor agar pengguna jasa dapat nyaman berada di Stasiun Bogor.

3) Kebersihan dan kenyamanan toilet

Berdasarkan kondisi dilapangan kebersihan toilet masih kurang nyaman yaitu toilet yang bau, lantai yang licin dan kotor, air yang kurang bersih dan tenaga kebersihan yang masih kurang sehingga dapat diberikan usulan pembersihan toilet lebih ditingkatkan, kedisiplinan dari pengguna toliet serta penambahan tenaga kebersihan toilet agar toilet selalu bersih dan nyaman sehingga kenyamanan pengguna jasa akan semakin meningkat.

4) Kenyamanan dan kemudahan naik/ turun penumpang (Peron)

Panjang peron berdasarkan panjang rangkaian kereta api, sedangkan untuk lebar peron dihitung berdasarkan jumlah penumpang, dengan rumus :

$$
b=\frac{0,64 m^{2} \text { per orang } \cdot V \cdot L F}{L}
$$

Keterangan :

$\mathrm{b}=$ Lebar Peron

$\mathrm{V} \quad=$ Jumlah rata-rata penumpang per jam sibuk dalam satu tahun (orang)

$\mathrm{LF}=$ Load factor (80\%)

$\mathrm{L} \quad=$ Panjang peron sesuai dengan rangkaian terpanjang kereta api penumpang yang beroperasi (meter)

Maka dapat dilakukan perhitungan untuk lebar peron dengan menggunakan perhitungan jumlah rata - rata penumpang per jam sibuk dalam satu tahun. Untuk tahun yang digunakan berdasarkan jumlah rata - rata penumpang per jam sibuk tahun 2014, yaitu 2278 penumpang. Untuk mengetahui seberapa besar lebar peron yang harus di siapkan beberapa tahun kedepan, maka dapat dilakukan perhitungan sebagai berikut.

$$
b=\frac{0,64 m^{2} \text { per orang } x 2277 \times 0.8}{290}=4,02 \mathrm{~m}^{2}
$$


Maka untuk lebar eksisting sekarang 3,6 m, maka untuk menampung penumpang beberapa tahun kedepan lebar peron masih kurang untuk dapat melayani dengan baik sehingga perlu dilakukan penambahan lebar peron. Selain itu terdapat beberapa peron yang yang masih mengguanakan peron rendah dan sedang yang mempersulit naik dan turun penumpang sehingga perlu dilakukan peninggian peron yang sesuai dengan tinggi KRL atau pemasangan bancik di peron tersebut untuk memberikan kemudahan dalam aksesibilitas pengguna jasi di Stasiun Bogor.

5) Ketersediaan informasi dan pengumuman perjalanan kereta Api

Analisis dilakukan berdasarkan tanggapan pengguna jasa berkaitan mengenai ketersediaan dan penempatan papan informasi dan pengumuman yang diatur dalam Peraturan Menteri Perhubungan Nomor 9 Tahun 2011 Tentang Standar Pelayanan Minimum Untuk Angkutan Orang Dengan Kereta Api. Maka dapat dilakukan rekomendasi dari hasil survei inventaris lapangan mengeni peningkatan kinerja stasiun dan pertimbangan pembenahan fasilitas informasi stasiun terkait kinerja atau pelayanan yang diberikan.

TABEL 4

FASILITAS INFORMASI

\begin{tabular}{|c|c|c|c|}
\hline FASILITAS & URAIAN & INDIKATOR & NILAI UKURAN \\
\hline $\begin{array}{l}\text { Fasilitas } \\
\text { Informasi }\end{array}$ & $\begin{array}{l}\text { a. Permasalahan pelayanan } \\
\text { visual } \\
\text { 1) Tulisan tidak terbaca } \\
\text { Jelas, } \\
\text { 2) Gambar tidak begitu } \\
\text { terlihat pada jadwal } \\
\text { pelayanan kereta api, } \\
\text { 3) Denah stasiun tidak } \\
\text { tersedia. }\end{array}$ & $\begin{array}{l}\text { a.Tempat } \\
\text { b.Terdapat di } \\
\text { sisi kiri dan } \\
\text { kanan yang } \\
\text { di letakan di } \\
\text { pintu masuk }\end{array}$ & $\begin{array}{l}\text { a. Diletakkan ditempat yang strategis, } \\
\text { b. Diletakkan ditempat yangmudah } \\
\text { dilihat, } \\
\text { c. Ditempatkan di tempat-tempat } \\
\text { yang dimaksud, } \\
\text { d. Berdasarkan jumlah pintu masuk } \\
\text { stasiun dan atau areal loket } \\
\text { penjualan tiket. }\end{array}$ \\
\hline & $\begin{array}{l}\text { b. Audio } \\
\text { Ketidak tepatan } \\
\text { informasi yang diberikan } \\
\text { mengenai kedatangan } \\
\text { kereta di stasiun, }\end{array}$ & $\begin{array}{l}\text { a. Tempat } \\
\text { b. Jumlah }\end{array}$ & $\begin{array}{l}\text { a. Ditempat yang strategis agar } \\
\text { mudah didengar oleh calon } \\
\text { penumpang, } \\
\text { b. Berdasarkan luas atau jumlah tuang } \\
\text { tunggu. }\end{array}$ \\
\hline
\end{tabular}

Sumber : Hasil Analisa 2015

Perlu penambahan mengenai papan informasi atau media Informasi yang berada di Stasiun Bogor untuk diletakan dekat loket maupun pintu masuk dan perlu pengaturan pembenahan letak penempatannya di area yang strategis dan mudah dilihat, serta penempatan audio di berbagai penjuru area stasiun agar mudah di dengar dan jelas pengumuman yang disampaikan kepada seluruh penggunan jasa di Stasiun Bogor.

\section{KESIMPULAN}

Rata-rata penilaian tingkat kepentingan dan kinerja pelayanan Stasiun Bogor dinilai dari hasil perhitungan CSI (customer satisfaction index) didapat nilai 62\% yang 
Hermawan | Analisis Peningkatan Pelayanan Stasiun Bogor Terhadap Kepuasan Pengguna Jasa Kereta Api Dengan Metode Importance Performance Analysis (IPA)

mengindikasikan tingkat kepuasan pengguna jasa terpenuhi terhadap pelayanan di Stasiun Bogor dan termasuk dalam kategori cukup puas.

Berdasarkan hasil analisis IPA dan perhitungan nilai kesenjangan (gap) terdapat lima buah yang atribut yang perlu diprioritaskan penanganannya, terlihat bahwa prioritas perbaikan atribut analisis IPA, dengan urutan berdasarkan atribut yang mempunyai nilai negatif yang paling besar dengan urutan pertama, yaitu:

1. Ketersediaan jumlah toilet $(-2.16)$

2. Ketersediaan dan kenyamanan ruang tunggu (waiting room) penumpang(-2.06)

3. Kebersihan dan kenyamanan toilet (-1.90)

4. Kenyamanan dan kemudahan naik/ turun penumpang (Peron) (-1.44)

5. Ketersediaan informasi dan pengumuman perjalanan kereta api (-1.37)

Keseluruhan atribut tersebut berada pada kuadran I dan hasil perhitungan nilai kesenjangan yang paling tinggi, maka penanganannya perlu diprioritaskan karena atribut inilah yang dinilai sangat penting oleh pengguna jasa, akan tetapi kinerjanya masih belum memuaskan.

\section{DAFTAR PUSTAKA}

Arikunto, S. 2004. Prosedur Penelitian: Suatu Pendekatan Praktek. Bandung: Rineka Cipta.

Kotler, Philip. 1995. "Manajemen Pemasaran Analysis Perencanaan dan Implementasi", Jakarta: Salemba Empat.

Kusumawardhani , L., Suliantoro, H., Puspitasari,B.N. 2010." Analisis Kualitas Pelayanan Dengan Menggunakan Integrasi Importance Performance Analysis (IPA) dan Model Kano (Studi Kasus di PT. Perusahaan Air Minum Lyonnaise Jaya Jakarta)", Jurnal Teknik Industri, Vol. 5, no. 3.

Martila, A., John and James C.John . 1997. "The Analysis Of The Importance and Satisfaction Level of The Customers". Prentice Hall Inc.

Peraturan Menteri Perhubungan Nomor 9 Tahun 2011 Tentang Standar Pelayanan Minimum Untuk Angkutan Orang dengan Kereta Api.

Pramyastiwi, Deasy Elfarischa, Imam Hardjanto, dan Abdullah Said. "Perkembangan Kualitas Pelayanan Perkeretaapian Sebagai Angkutan Publik Dalam Rangka Mewujudkan Transportasi Berkelanjutan (Studi pada PT Kereta Api Indonesia Daerah Operasi 8 Surabaya)". Jurnal Administrasi Publik (JAP), Vol.1. No.3. hal. 61-69: Universitas Brawijaya, Malang.

Rangkuti, F. 2002. The Power of Brands. Jakarta : PT. Gramedia Pustaka Utama.

Santoso, Singgih. 2000. "Menggunakan SPSS dan Excel untuk Mengukur Sikap dan Kepuasan Konsumen", Jakarta: Elex Media Computindo.

Sholihah, Neny Mita. 2010. "Analisis Kualitas Pelayanan Kereta Api Berdasarkan Model Importance Performance Analysis (IPA) dan Kano (Suatu Studi di KA DAOP II Bandung)", Universitas Widyatama, Bandung.

Siagian, D. 2002. "Metode Statistika Untuk Bisnis dan Ekonomi". Jakarta: PT. Gramedia Pustaka Utama,.

Sugiyono. 1999. "Statistika untuk Penelitian", Bandung: Penerbit Alfabeta.

Uyanto, Stanislaus S. 2006. " Pedoman Analisis Data dengan SPSS", Jakarta: Graha Ilmu. 